\title{
3.5 Mbit/sec. MARS Modulator System Performance for Fiber-to-the-Home Applications
}

\author{
J.A. Walker', K.W. Goossen', P.P. Iannone ${ }^{2}$, W.M. MacDonald ${ }^{3}$, R. Ruel ${ }^{3}$, R. Boie ${ }^{4}$, S.C. Amey ${ }^{3}$, N.J. Frigo², \\ and D.J. Bishop ${ }^{3}$ \\ ${ }^{1}$ Bell Laboratories, Lucent Technologies, 101 Crawfords Comer Rd., Rm 4B-511, Holmdel, NJ 07733 \\ ${ }^{2}$ Bell Laboratories, Lucent Technologies, Murray Hill, NJ \\ ${ }^{3}$ AT\&T Research, Holmdel, NJ \\ ${ }^{4}$ AT\&T Research, Murray Hill, NJ
}

\section{INTRODUCTION}

Wavelength Division Multiplexed Passive Optical Network Systems (WDM-PONS) show promise of providing a costeffective method of obtaining fiber-to-the-home telecommunications networks. The Mechanical Anti-Reflection Switch (MARS) optical modulator has been developed for use as a moderate datarate (a few Mbit/sec.) component for a class of WDM-PONS systems utilizing "loop-back" principles [1]. Loop-back refers to systems which utilize a modulator at the subscriber node to overmodulate light sent downstream from the central office to the user and loop it back upstream to the central office. An important advantage of this type of WDM system is the ability to cost sh are high performance sources and detectors at the central office while utilizing unshared, low cost, moderate performance components at the subscriber node.

a)

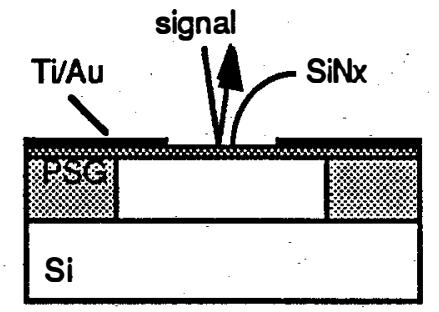

b)

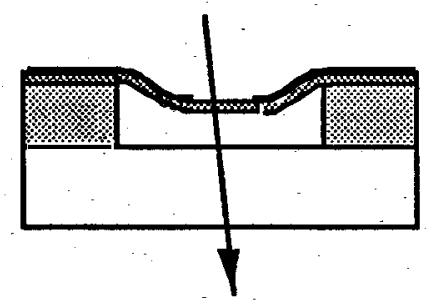

Figure 1: MARS modulation principle.

A difficulty arises from the fact that these low cost components must still meet some rather challenging requirements, moderate data rate ( $>1 \mathrm{Mbit} / \mathrm{sec}$.), wide spectral width in order to provide many wavelength channels, high contrast ratio $(>10 \mathrm{~dB}$ modulation depth), and good thermal stability. The MARS modulator has been demonstrated to meet or surpass all of these requirements as well as allow extremely inexpensive optical packaging techniques to be used in order to reduce the cost of the fully packaged device. The performance and packaging cost implications of the MARS device are discussed here.

\section{MARS DEVICE PRINCIPLE}

The MARS device is an optical modulator based on the principle of a vertically moving anti-reflection film suspended above a silicon substrate [2]. The operating principle and device structure are shown in Fig. 1. Anti-reflection films are well known in the optics community, and are formed by depositing a dielectric film upon the surface desired to be anti-reflective. The dielectric film is required to have a

refractive index equal to $\sqrt{n s}$ (where $n_{a}$ is the refractive index of the substrate) and a thickness equal to $\lambda_{d} / 4$ where $\lambda_{0}$ is the center wavelength of the incident light spectrum. If this antireflection film is suspended above the substrate by an air gap equal to $\lambda d 4$, instead of an anti-reflecting condition, a highly reflecting condition is then achieved. This reflecting/antireflecting condition holds for all air gaps equal to $m \lambda d 4$, reflecting if $m$ is odd, anti-reflecting if $m$ is even. As $m$ increases however, the spectral width of the device narrows, reducing the number of wavelength channels for which a modulator could operate. The operating principles of the MARS device are discussed more thoroughly in Reference 2, and the fabrication is discussed in Reference 3.

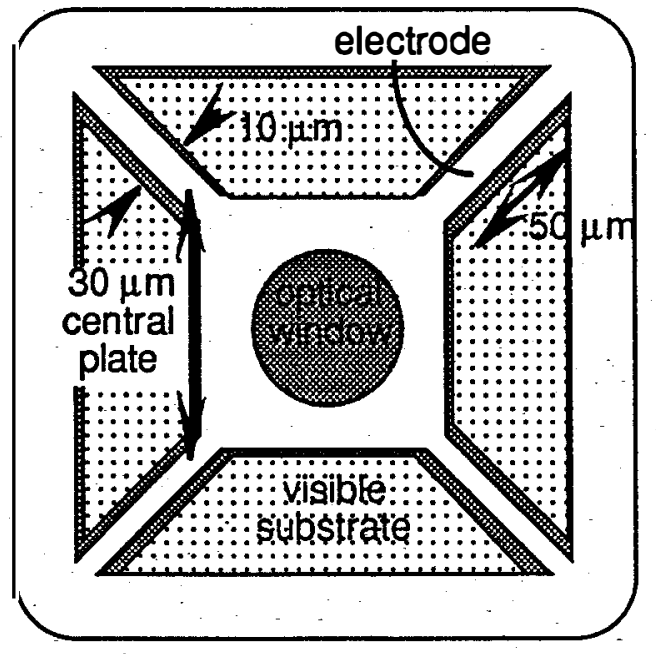

Figure 2: Top view of a MARS design.

A typical device geometry is shown in Fig. 2. The MARS consists of a central plate suspended above the substrate via support beams, comprising the mechanically active area of the device. An optical window is defined by the absence of electrode material in the center of the plate area. Modulators 
with central plates ranging from $10 \mu \mathrm{m} \times 10 \mu \mathrm{m}$ to $100 \mu \mathrm{m} \times$ $100 \mu \mathrm{m}$, suppori beams ranging from $4 \mu \mathrm{m}$ wide to $21 \mu \mathrm{m}$ wide, and $5 \mu \mathrm{m}$ long to $100 \mu \mathrm{m}$ long have been fabricated and tested.

\section{SYSTEM PERFORMANCE}

Typically rise and fall imes of roughly $130 \mathrm{~ns}$ are measured for standard modulators. With some device geometries, the response includes mechanical ringing at characteristic resonant frequencies of up to $4 \mathrm{MHz}$. With straight forward device design changes, this ringing can be reduced and modeling predicts that usable data rates can be achieved at three times the resonant frequency of a device, or up to $12 \mathrm{Mbit} / \mathrm{sec}$. In practice however, we have yet to demonstrate system operation at such high data rates. System experiments have been run to determine bit-error-rates for fully packaged devices under normal operating conditions. The measurement apparatus used for system tests is shown in Figure 3. Figure 4 shows the response of such a modulator to a pseudo random bit stream of $2^{15}-1$ word length at $3.5 \mathrm{Mbit} / \mathrm{sec}$.

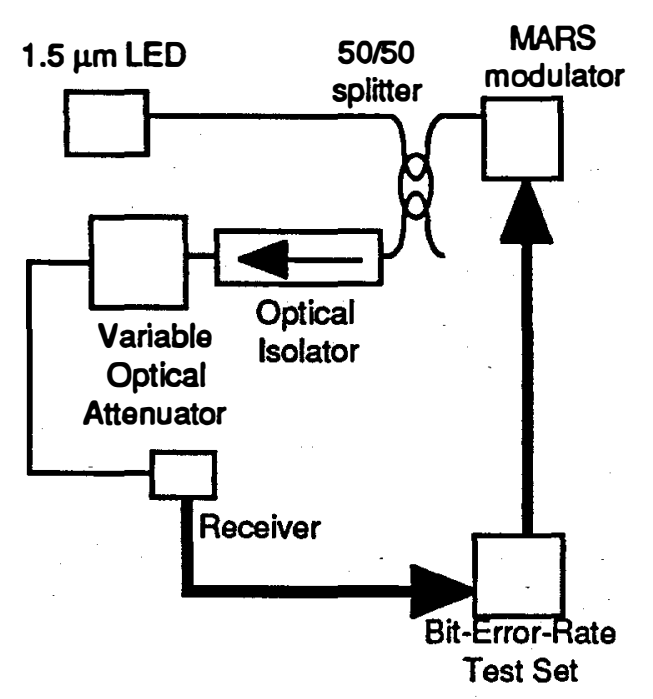

Figure 3: Bit-error-rate measurement apparatus.

As shown in Fig. 4, the modulator can achieve this data rate with error rates of less than $10^{-6}$ with less than $2 \mathrm{~dB}$ power penalty from the system base band. This penalty arises mainly from pattem dependent inter-symbol interference.

\section{PACKAGING CONSIDERATIONS}

The final cost of a packaged MARS modulator will be dominated by the expense of the packaging process, particularly optical fiber attachment. Here, the MARS modulator has some distinct advantages. Due to the large optical window (20-30 $\mu \mathrm{m})$, inherent polarization insensitivity, and uncomplicated fabrication, multi-mode packaging techniques can be exploited to obtain single-mode fiber devices. Measurements show an alignment tolerance an order of magnitude larger than typical single mode devices, large enough to enable passive packaging techriques. This would eliminate the expensive active alignment process used for most photonic packages today, greatly reducing cost.



Figure 4: BER result and eye pattem for a fully packaged modulator.

\section{CONCLUSION}

We have demonstrated a micromechanical modulator with the capability of providing upstream data rates of $3.5 \mathrm{Mbit} / \mathrm{sec}$ with $10^{-2} \mathrm{BER}$ in a fiber-to-the-home communications system. Due to several advantageous aspects of the MARS, packaging costs for the device should be quite low, resulting in an extremely inexpensive moderate data rate optical modulator.

\section{REFERENCES}

[1] N.J. Frigo, P.P. Iannone, P.D. Magill, T.E. Darcie, M.M. Downs, B.N. Desai, U.Koren, T.L. Koch, C. Dragone, H.M. Presby, and B.E. Bodeep, "A wavelength-division multiplexed passive optical network with cost-shared components," IEEE Phot. Tech. Lett., vol. 6, pp. 1365 1367, (1994).

[2] K.W. Goossen, J.A. Walker, and S.C. Amey, "Silicon modulator based on mechanically-active anti-reflection layer with $1 \mathrm{Mbit} / \mathrm{sec}$. capability for fiber-in-the-loop applications," IEEE Phot. Tech. Lett., vol. 6, pp. 11.19. 1121, (1994).

[3] J.A. Walker, K.W. Goossen, and S.C. Amey, "Fabrication of a mechanical anti-reflection switch for fiber to the home systems," J. Micromech. Syst., vol. 5, no. 1, pp. 45-51, (1996). 